\title{
Balloon dilatation of the aortic valve: limited success and early restenosis
}

\author{
MARK DANCY, * KEITH DAWKINS, $\dagger$ DAVID WARD* \\ From the ${ }^{\star}$ South West Thames Regional Cardiothoracic Unit, St George's Hospital, London and the $\dagger$ Wessex \\ Cardiothoracic Centre, Southampton General Hospital, Shirley, Southampton
}

SUMMARY Balloon dilatation of the aortic valve was attempted 16 times in 15 patients with severi aortic stenosis. None died but one had a transient stroke after the procedure. At dilatation the gradient across the aortic valve was reduced by $>30 \%$ in $69 \%$ of patients and the Gorlin valve areigy (calculated in $7 / 15$ patients) increased by $30 \%$ in half. But a comparison of Doppler gradient $\$$ measured before and one to two days after dilatation in 11 patients showed a $>30 \%$ reduction in the simultaneously measured gradient in only four. Doppler gradient was the most accurat $\overrightarrow{\mathrm{E}}$ predictor of symptomatic benefit and a fall in Doppler gradient persisted mainly in patients whos peak to peak gradient fell by at least $40 \%$ at the time of the procedure.

Balloon dilatation of the aortic valve is a relatively safe procedure but it is less successful that previous reports suggest, perhaps because of early restenosis. Some forms of aortic stenosis may b\& more amenable to this procedure than others.

Since the original description by Cribier ${ }^{1}$ of balloon dilatation of the aortic valve in adults with severe aortic stenosis several centres have adopted the technique. Although its success is not yet established early results suggest an improvement in symptoms in a high proportion of patients..$^{2-6} \mathrm{Few}$ data are available on longer term success although Cribier's group has reported a restenosis rate of $22 \%$ at a mean of 17 weeks after the dilatation. Our early results differ from those already published.

\section{Patients and methods}

Fifteen elderly patients (mean (SD) age $77(5.5)$ years) with severe aortic stenosis were recommended for balloon dilatation of the aortic valve because they were not suitable for aortic valve replacement (table 1). In some patients operation was absolutely contraindicated, while in others balloon dilatation was carried out because it had a lower risk than aortic valve replacement. Table 2 shows details of the procedure. We used balloons with diameters of 12$25 \mathrm{~mm}$. Some were single chamber (Mansfield Single Lumen) and some were triple lumen Trefoil $(21 \mathrm{~mm}$ or $25 \mathrm{~mm}$ ). Simultaneous aortic valve gradients were

Requests for reprints to Dr Mark Dancy, Central Middlesex Hospital, Acton Lane, London NW10 7NS.

Accepted for publication 18 May 1988
Table 1 Patient details and reasons for balloon dilatation of the aortic valve

\begin{tabular}{|c|c|c|c|c|}
\hline Patient & Age & Sex & Symptoms ${ }^{\star}$ & $\begin{array}{l}\text { Reason for } \\
\text { balloon } \\
\text { dilatation }\end{array}$ \\
\hline $\begin{array}{l}1 \\
2 \\
3 \\
4\end{array}$ & $\begin{array}{l}79 \\
85 \\
71 \\
73\end{array}$ & $\begin{array}{l}\mathrm{F} \\
\mathrm{F} \\
\mathrm{M} \\
\mathrm{M}\end{array}$ & $\begin{array}{l}\text { D IV, A IV } \\
\text { D IV } \\
\text { S, A II } \\
\text { A II, D II }\end{array}$ & $\begin{array}{l}\text { Frail } \\
\text { Frail } \\
\text { Frail } \\
\text { Disseminate } \\
\text { carcinoma }\end{array}$ \\
\hline $\begin{array}{l}5 \\
6 \\
7 \\
8\end{array}$ & $\begin{array}{l}89 \\
82 \\
68 \\
76\end{array}$ & $\begin{array}{l}\mathbf{M} \\
\mathrm{F} \\
\mathrm{F} \\
\mathrm{M}\end{array}$ & $\begin{array}{l}\text { D IV } \\
\text { A IV, D III } \\
\text { D IV } \\
\text { D IV, A II }\end{array}$ & $\begin{array}{l}\text { Age } \\
\text { Frail } \\
\text { Frail } \\
\text { Pulmonary } \\
\text { disease }\end{array}$ \\
\hline $\begin{array}{r}9 \\
10 \\
11 \\
12 \\
13 \\
14\end{array}$ & $\begin{array}{l}77 \\
81 \\
75 \\
76 \\
76 \\
72\end{array}$ & $\begin{array}{l}F \\
M \\
F \\
F \\
F \\
M\end{array}$ & $\begin{array}{l}\text { D IV, A II } \\
\text { D IV } \\
\text { D IV, A III, S } \\
\text { S } \\
\text { D IV } \\
\text { D IV, A III }\end{array}$ & $\begin{array}{l}\text { Frail } \\
\text { Carcinoma } \\
\text { Frail } \\
\text { Carcinoma } \\
\text { Stroke } \\
\text { Pulmonary }\end{array}$ \\
\hline 15 & 79 & F & D IV & $\begin{array}{l}\text { Frail, } \\
\text { diabetes }\end{array}$ \\
\hline
\end{tabular}

$\star D$, dyspnoea; A, angina; S, syncope; I-IV, New York Hear Association grades of exertion necessary to produce symptoms.

recorded either with a second catheter in the aorta by comparison with femoral arterial pressure aftex measurement of downstream augmentation. WE measured cardiac output by thermodilution in sevent patients before and after dilatation and calculated the area of the aortic valve by the Gorlin formula ${ }^{8}$ usin pressure recordings taken within one minute of the 
Table 2 Details of procedure

\begin{tabular}{cllll}
\hline Patient & Approach & $C A D^{\star}$ & Balloon type & $\begin{array}{l}\text { Balloon } \\
\text { size }(\mathrm{cm})\end{array}$ \\
\hline 1 & Femoral & 0 & Triple lumen & $2 \cdot 1$ \\
2 & Femoral & $?$ & Single lumen & $1 \cdot 2$ \\
3 & Brachial & 0 & Single lumen & $2 \cdot 0$ \\
4 & Brachial & 0 & Triple lumen & $2 \cdot 1$ \\
5 & Femoral & $3 \mathrm{VD}$ & Single lumen & $1 \cdot 5^{\star}$ \\
& $\times 2$ & & Single lumen & $1 \cdot 2^{\star}$ \\
6 & Femoral & 0 & $1 \cdot 2^{\star}$ \\
& $\times 2$ & & Single lumen & $1 \cdot 2^{\star}$ \\
7 & Femoral & 0 & $2 \cdot 0$ \\
$8 \mathrm{a}$ & Brachial & 0 & Single lumen & $1 \cdot 2$ \\
$8 \mathrm{~b}$ & Femoral & 0 & Single lumen & $1 \cdot 2^{\star}$ \\
& $\times 2$ & & & $1 \cdot 2^{\star}$ \\
9 & Femoral & $?$ & Triple lumen & $2 \cdot 1$ \\
10 & Femoral & $?$ & Single lumen & $2 \cdot 0$ \\
11 & Femoral & $?$ & Single lumen & $2 \cdot 0$ \\
12 & Femoral & $?$ & Triple lumen & $2 \cdot 1$ \\
13 & Femoral & 0 & Triple lumen & $2 \cdot 1,2 \cdot 5$ \\
14 & Brachial & 0 & Single lumen & $2 \cdot 0$ \\
15 & Femoral & $2 \mathrm{VD}$ & Single lumen & $2 \cdot 5$ \\
& & & $2 \cdot 0$ \\
\hline
\end{tabular}

*Two balloon technique.

$\mathrm{CAD}$, coronary artery disease; $\mathrm{VD}$, vessel disease.

cardiac output measurement. The aortic valve gradient was also estimated by Doppler echocardiography one to two days before and again one to two days after the procedure. We crossed the aortic valve with a guide wire and advanced the balloon catheter across the aortic valve. For the first patients we used a manometer to monitor the inflation of the balloon to $6 \mathrm{~atm}$, but later we assessed full inflation by visual appearance. If the positioning of the balloon was unstable it was inflated slowly initially and then rapidly fully expanded in an attempt to lock it in place. In one patient the balloon was inflated in the left ventricle and pulled back into the aorta. Inflations were maintained for $15-30$ seconds. Patient 8 underwent two separate procedures, so there were 16 procedures in 15 patients.

\section{Results}

The mean (SD) peak to peak pressure drop across the aortic valve before the procedure was 86 (29) $\mathrm{mm} \mathrm{Hg}$ (table 3). Immediately after the procedure the mean gradient had fallen to 59 (29) $\mathrm{mm} \mathrm{Hg}$. Eleven procedures were attended by a fall in the aortic valve gradient of $>30 \%$ and five out of seven patients showed a rise in Gorlin valve area. We measured gradients by Doppler echocardiography before and after 13 procedures. Only four patients showed a decrease of $>30 \%$. The mean value fell from 90 (27) $\mathrm{mm} \mathrm{Hg}$ to $75(28) \mathrm{mm} \mathrm{Hg}$. In four patients there was an improvement in dyspnoea that persisted for at least one month. Two of these patients had Doppler gradients of $100 \mathrm{~mm} \mathrm{Hg}$ both before and after balloon dilatation. One patient had symptomatic improvement for two days. One patient had no further syncope (her only symptom). Nine patients experienced no relief of symptoms.

There were several complications, mostly minor. In one patient pulmonary oedema developed during a first unsuccessful dilatation, and a small stroke developed that resolved completely after a second unsuccessful procedure. Systolic aortic pressure had fallen by $\geqslant 30 \mathrm{~mm} \mathrm{Hg}$ in six patients at the end of the procedure. One patient required transfusion and another needed fluid replacement for symptomatic hypotension. In one patient a ruptured right external iliac artery was repaired.

Seven patients were referred for operation after one or two unsuccessful attempts at balloon dilata-

Table 3 Invasive and non-invasive assessment of aortic valve gradient before (pre) and after (post) dilatation.

(s) = symptomatic benefit

\begin{tabular}{|c|c|c|c|c|c|c|c|c|c|}
\hline \multirow[b]{3}{*}{ Patient } & \multicolumn{7}{|c|}{ Invasive assessment } & \multirow{2}{*}{\multicolumn{2}{|c|}{$\begin{array}{l}\text { Non-invasive assessment } \\
\text { Doppler aortic valve } \\
\text { gradient ( } \mathrm{mm} \mathrm{Hg} \text { ) }\end{array}$}} \\
\hline & \multicolumn{2}{|c|}{$\begin{array}{l}\text { Aortic valve gradient } \\
(\mathrm{mm} \mathrm{Hg})\end{array}$} & \multicolumn{2}{|c|}{$\begin{array}{l}\text { Cardiac output } \\
\text { (l/min) }\end{array}$} & \multicolumn{2}{|c|}{$\begin{array}{l}\text { Aortic valve area } \\
\left(\mathrm{cm}^{2}\right)\end{array}$} & \multirow{2}{*}{$\begin{array}{l}\text { Change in } \\
\text { systolic } B P \\
(\mathrm{~mm} H g)\end{array}$} & & \\
\hline & $\overline{P r e}$ & Post & Pre & Post & $\overline{P r e}$ & Post & & $\overline{\text { Pre }}$ & Post \\
\hline $\begin{array}{l}1 \\
2 \\
3 \\
4 \\
5(\mathrm{~s}) \\
6 \\
7 \\
8 \mathrm{a} \\
8 \mathrm{~b} \\
9(\mathrm{~s}) \\
10(\mathrm{~s}) \\
11(\mathrm{~s}) \\
12(\mathrm{~s}) \\
13 \\
14 \\
15\end{array}$ & $\begin{array}{r}100 \\
80 \\
115 \\
70 \\
40 \\
150 \\
100 \\
90 \\
65 \\
75 \\
90 \\
70 \\
70 \\
65 \\
60 \\
140\end{array}$ & $\begin{array}{r}50 \\
55 \\
80 \\
40 \\
5 \\
100 \\
100 \\
30 \\
40 \\
35 \\
60 \\
70 \\
40 \\
80 \\
50 \\
110\end{array}$ & $\begin{array}{l}4 \cdot 6 \\
2 \cdot 3 \\
\overline{3} \cdot 8 \\
2 \cdot 0 \\
2 \cdot 4 \\
3 \cdot 1 \\
- \\
- \\
- \\
- \\
- \\
-2\end{array}$ & $\begin{array}{l}4 \cdot 6 \\
2 \cdot 1 \\
\overline{4 \cdot 7} \\
1 \cdot 6 \\
2 \cdot 2 \\
3 \cdot 31 \\
- \\
- \\
- \\
- \\
- \\
8 \cdot 4 \\
-\end{array}$ & $\begin{array}{l}0.67 \\
0.33 \\
- \\
0.61 \\
0.41 \\
0.22 \\
0.40 \\
- \\
- \\
- \\
- \\
- \\
0.77 \\
-\end{array}$ & $\begin{array}{l}0.78 \\
0.29 \\
\overline{0.83} \\
0.83 \\
0.26 \\
0.61 \\
- \\
- \\
- \\
- \\
- \\
0.74 \\
-\end{array}$ & $\begin{array}{lr}+ & 10 \\
- & 50 \\
& 0 \\
+ & 25 \\
- & 15 \\
+ & 10 \\
-110 \\
+\quad 5 \\
& 0 \\
& 0 \\
-\quad 10 \\
-\quad 50 \\
-\quad 30 \\
-\quad 30 \\
-100\end{array}$ & $\begin{array}{c}90 \\
70 \\
90 \\
65 \\
30 \\
- \\
125 \\
80 \\
70 \\
120 \\
100 \\
100 \\
120 \\
110 \\
- \\
-\end{array}$ & $\begin{array}{c}80 \\
70 \\
90 \\
65 \\
16 \\
- \\
135 \\
70 \\
65 \\
64 \\
100 \\
100 \\
64 \\
65 \\
- \\
-\end{array}$ \\
\hline
\end{tabular}


tion. Three had senile tricuspid aortic stenosis without commisural fusion. Three had bicuspid valves. At operation none of these valves showed any evidence of being disrupted by balloon dilatation. In the patient with a rheumatic valve there was partial release of the fused commisures after dilatation. Inspection of the heart distant from the valve showed damage to the left ventricle in three patients that was presumably caused by balloon dilatation. Two patients had bruising of the apex, and in one of them there was an apical thrombus. This patient had a stroke at the time of the second balloon dilatation, which suggested that the second procedure might have dislodged an apical thrombus formed after the first procedure. One patient had bruising over the territory of the left anterior descending coronary artery that was associated with a significant haemopericardium.

Subsequent operation was complicated by anterior myocardial infarction in the patient with apical thrombus (who had normal coronary arteries) and another patient had a major stroke and died.

\section{Discussion}

The incidence of aortic stenosis rises with age and although replacement is the best treatment some patients are not suitable for major surgery while in others the risk of the procedure is too high. For this reason the prospect of a low risk percutaneous procedure that can at least palliate the condition is attractive. Cribier's pioneering work and the early results from other laboratories suggest that the risks associated with balloon dilatation are low and that the procedure produces an immediate acceptable reduction of $40-50 \%$ in the pressure drops across the aortic valve. Furthermore, many patients have reported an improvement in symptoms that persisted for several months. ${ }^{26}$ So far there are few data on long term follow up.

Our results for the improvement measured at the time of the procedure resemble those of other groups. The aortic valve gradient was reduced by mean (SD) of $32(26) \%$, and the area of the aortic valve increased in five of the seven patients for whom it could be calculated. But there were appreciable changes in cardiac output during the procedure that made the haemodynamic assessment less reliable. For example, one patient in whom the aortic valve gradient remained unchanged showed a significant increase in aortic valve area because cardiac output increased. This emphasises the importance of using area rather than gradient to assess the effects of dilatation. Assessment of aortic valve gradient by Doppler echocardiography may be more reliable because it is made in the basal state in a relaxed, pain-free, and haemodynamically stable patient. Although pressure drops across the aortic valve measured by Doppleir echocardiography do not always correlate with those measured at catheterisation intra-patient compapisons of Doppler measurements are likely to be moxe accurate. In the present study the results of assest ment by Doppler echocardiography were disappoif ting, but they correlated well with symptomatic benefit in all but two patients, who had an improvement in symptoms despite there being reduction in Doppler gradient.

We encountered similar difficulties as those of other groups. The most life threatening is perfor tion of the left ventricle by the guide wire. attempted to form a large loop of guide wire in the leff ventricle, and we found that a J-tipped exchange guide wire with a large diameter curve was best for this purpose. The use of longer balloons and rapged inflations may increase balloon stability, but larger balloons may be difficult to inflate and deflate rapidlop For this reason we no longer use manometers for inflation and are guided by the appearance of the balloon on the image intensifier. Stiffer catheters and guide wires increase the stability of the balloon position and pressure on the guide wire counteracts the tendency for the balloon to be pushed across the valve from its position in the left ventricle.

Seven patients proceeded to aortic val replacement because their symptoms were nồ relieved by balloon dilatation. In only one patienit was there any visual evidence that the preceding balloon dilatation had appreciably altered the valve This was the only rheumatic valve in the series and the fused commisures were partially split. Valves with commisural fusion might be expected to res pond to balloon dilatation, and if this were true rheumatic valves should be the easiest to dilate. Som bicuspid valves have a small amount of commisura fusion but the main mechanism of stenosis is increased rigidity and calcification of the valve cusps themselves. Senile tricuspid aortic stenosis is als caused by rigidity of cusps rather than by commisura fusion.

We know that the technique and equipment have improved since we treated this group of patients. even so a comparison of our early results and the ear $\overrightarrow{\text { B }}$ results of others who used similar techniques remain valid. The shortcomings of the technique may bf reduced by developments in equipment and refinements in patient selection, but it is likely that proportion of "suitable" patients will not respond to balloon dilatation despite advances in technique.

Balloon dilatation is already an importanf palliative clinical tool and will complement operation in the treatment of calcific aortic stenosis in certain groups of patients. If our results are confirmed by 
others and balloon dilatation is less successful than previous reports suggest, it would be an advantage to be able to select patients with valves that are most likely to be successfully dilated. This depends on establishing the underlying aetiology of the aortic stenosis and on relating this to the success rates.

We thank Dr C Pumphrey and Dr D Redwood for allowing us to include data on their patients.

\section{References}

1 Cribier A, Saondi N, Berland J, Savin T, Rocha P, Letac B. Percutaneous transluminal valvuloplasty of acquired aortic stenosis in elderly patients: an alternative to valve replacement? Lancet 1986;i:63-7.

2 Jackson G, Thomas S, Monoghan M, Forsyth A, Jewitt $D$. Inoperable aortic stenosis in the elderly: benefit from percutaneous transluminal valvuloplasty. $\mathrm{Br}$ Med $J$ 1987;294:83-6.
3 McKay RG, Safian RD, Locke JE, et al. Balloon dilatation of calcific aortic stenosis in elderly patients: postmortem, intraoperative, and percutaneous valvuloplasty studies. Circulation 1986;74:119-25.

4 Cribier A, Savin T, Berland J, et al. Percutaneous transluminal balloon valvuloplasty of adult aortic stenosis: report of 92 cases. J Am Coll Cardiol 1987;9:381-6.

5 Isner JM, Salem D, Desnoyers MR, et al. Treatment of calcific aortic stenosis by balloon valvuloplasty [Abstract]. J Am Coll Cardiol 1987;9:13.

6 Drobinski G, Lechat Ph, Metzger J Ph, Lepailleur Ce, Vacheron A, Grosgogeat Y. Results of percutaneous catheter valvuloplasty for calcified aortic stenosis in the elderly. Eur Heart $J$ 1987;8:322-8.

7 Letac B, Berland J, Mechameche R, Savin T, Saondi N, Cribier A. Late haemodynamic evaluation after percutaneous aortic valvuplasty in adults with aortic stenosis [Abstract]. J Am Coll Cardiol 1987;9:14.

8 Gorlin R, Gorlin G. Hydraulic formula for calculation of area of stenotic mitral valve, other cardiac valves and central circulatory shunts. Am Heart $J$ 1951;41:1-10. 